\title{
Iron-resonant valence band photoemission and oxygen near edge $x$-ray absorption fine structure study on $\mathrm{La}_{1-\mathrm{x}} \mathrm{Sr}_{\mathrm{x}} \mathrm{Fe}_{0.75} \mathrm{Ni}_{0.25} \mathrm{O}_{3-\delta}$
}

\author{
Selma Erat, ${ }^{1,2, a)}$ Hiroki Wadati, ${ }^{3}$ Funda Aksoy, ${ }^{4,5}$ Zhi Liu, ${ }^{5}$ Thomas Graule, ${ }^{1,6}$ \\ Ludwig J. Gauckler, ${ }^{2}$ and Artur Braun ${ }^{1, a)}$ \\ ${ }^{1}$ Laboratory for High Performance Ceramics, Empa-Swiss Federal Laboratories for Materials Science \\ \& Technology, CH-8600 Dübendorf, Switzerland \\ ${ }^{2}$ Department for Materials, Nonmetallic Inorganic Materials, ETH Zürich, Swiss Federal Institute \\ of Technology, CH-8037 Zürich, Switzerland \\ ${ }^{3}$ Department of Physics and Astronomy, University of British Columbia, Vancouver \\ British Columbia V6T 1Z4, Canada \\ ${ }^{4}$ Department of Physics, Cukurova University, TR-01330 Adana, Turkey \\ ${ }^{5}$ Advanced Light Source, Ernest Orlando Lawrence Berkeley National Laboratory, Berkeley, \\ California 94720, USA \\ ${ }^{6}$ Technische Universität Bergakademie Freiberg, D-09596 Freiberg, Germany
}

(Received 12 July 2010; accepted 11 August 2010; published online 21 September 2010)

\begin{abstract}
Iron resonant valence band photoemission spectra (VB PES) of $\mathrm{Sr}$ substituted $\mathrm{LaFe}_{0.75} \mathrm{Ni}_{0.25} \mathrm{O}_{3-\delta}$ have been recorded across the Fe $2 p-3 d$ absorption threshold to obtain Fe specific spectral information on the $3 d$ projected partial density of states. Comparison with $\mathrm{La}_{1-\mathrm{x}} \mathrm{Sr}_{\mathrm{x}} \mathrm{FeO}_{3}$ resonant VB PES literature data suggests that substitution of $\mathrm{Fe}$ by Ni forms electron holes which have mainly $\mathrm{O} 2 p$ character. Substitution of La by $\mathrm{Sr}$ increases the hole concentration to an extent that the $\mathrm{e}_{\mathrm{g}}$ structure vanishes. The variation in the $\mathrm{e}_{\mathrm{g}}$ and $\mathrm{t}_{2 \mathrm{~g}}$ structures is paralleled by the changes in the electrical conductivity. (C) 2010 American Institute of Physics. [doi:10.1063/1.3484960]
\end{abstract}

The electronic structure of defect regulated materials is important for understanding their functional relationship such as transport properties. The electrical conductivity of oxides with perovskite structure depends on their valence band (VB) characteristic. ${ }^{1} \mathrm{La}_{1-x} \mathrm{Sr}_{x} \mathrm{FeO}_{3-\delta}$ (LSFO) is a parent compound that can be used in solid oxide fuel cell cathodes, ${ }^{2}$ and the conductivity particularly at high temperature is an important quantity for its functionality as a cathode. Sr substitution of $\mathrm{LaFeO}_{3}$, which is an insulator, forms electron holes which are associated with nominally tetravalent Fe having the electronic structure of $3 d^{5} \underline{\mathrm{L}}, \underline{\mathrm{L}}$ denoting the electron hole from the oxygen. Substitution by $50 \%$ $\left(\mathrm{Fe}^{3+} / \mathrm{Fe}^{4+}=1 / 1\right)$ warrants that the electron hopping across the $\mathrm{Fe}^{3+}-\mathrm{O}-\mathrm{Fe}^{4+}$ superexchange unit occurs with maximum probability. It has been shown that $\mathrm{Fe}$ substitution of $\mathrm{La}_{1-x} \mathrm{Sr}_{x} \mathrm{FeO}_{3-\delta}$ on the B-site by Ni (Ref. 3) or Co improves the conductivity, with a conductivity maximum at temperatures around $650-750 \mathrm{~K}$, making them attractive for intermediate temperature proton conducting ceramic fuel cells. ${ }^{4}$ The structural and transport properties of $\mathrm{La}_{1-\mathrm{x}} \mathrm{Sr}_{\mathrm{x}} \mathrm{Fe}_{1-\mathrm{y}} \mathrm{Ni}_{\mathrm{y}} \mathrm{O}_{3-\delta}$ have been studied for different stoichiometries $(x, y){ }^{5-7}$ It has also been explained how the electronic structure evolves from charge transfer-type insulator $\mathrm{LaFeO}_{3}(2 \mathrm{eV}$ band gap) to the "oxygen-hole metal" $\mathrm{SrFeO}_{3}$ (Ref. 8) using in situ photoemission spectroscopy (PES) on thin films. Out of the rare-earth nickel oxides, $\mathrm{LaNiO}_{3}$ is the only metallic member. ${ }^{9}$ Chainani et al. ${ }^{10}$ showed a systematic X-ray photoemission study on bulk LSFO. However, the influences of $\mathrm{Ni}$ and $\mathrm{Sr}$ substitution on electronic structure, especially for occupied states of Fe, are still not clear.

We employ Fe resonant VB PES to investigate the influence of the Ni-substitution and $\mathrm{Sr}$-substitution with respect to

\footnotetext{
${ }^{a}$ Authors to whom correspondence should be addressed. Electronic addresses: selmaerat33@gmail.com and artur.braun@alumni.ethz.ch. Tel.: +4144823 4850. FAX: +41448234150.
}

the $\mathrm{Fe}$, which is the main player for the electrical conductivity via the $\mathrm{Fe}^{3+}-\mathrm{O}-\mathrm{Fe}^{4+}$ superexchange unit.

The A-site substitution of $\mathrm{LaFeO}_{3}$ by $\mathrm{Sr}\left(\mathrm{La}_{1-\mathrm{x}} \mathrm{Sr}_{\mathrm{x}} \mathrm{FeO}_{3}\right)$ and its impact on the electronic conductivity is well understood. In the oxygen near edge $\mathrm{x}$-ray absorption fine structure (NEXAFS) spectra this substitution manifests in a so called hole doping state with $\mathrm{e}_{\mathrm{g}} \uparrow$ symmetry as the leading peak in the $\mathrm{O} 1 \mathrm{~s}$ pre-edge, preceding the two $\mathrm{t}_{2 \mathrm{~g}} \downarrow$ and $\mathrm{e}_{\mathrm{g}} \downarrow$ orbital symmetry peaks from the hybridized $\mathrm{O} 2 p-\mathrm{Fe} 3 d$ states. Interestingly, B-site substitution with $\mathrm{Ni}$, too, shows such extra peak. The question naturally arises as to which role $\mathrm{Fe}$ and $\mathrm{Ni}$ play for the corresponding spectra.

High purity precursors $\left(\mathrm{La}_{2} \mathrm{O}_{3}>99.99 \%, \mathrm{SrCO}_{3}, 99.9\right.$ $\% \mathrm{Fe}_{2} \mathrm{O}_{3}>99.0 \%$, and $\mathrm{NiO} 99.8 \%$, purities given in weight $\%)$ were mixed in stoichiometric proportions, ball milled for $24 \mathrm{~h}$, calcined for $4 \mathrm{~h}$ at $1473 \mathrm{~K}$ and for $12 \mathrm{~h}$ at $1673 \mathrm{~K}$ so as to obtain $\mathrm{La}_{1-\mathrm{x}} \mathrm{Sr}_{\mathrm{x}} \mathrm{Fe}_{0.75} \mathrm{Ni}_{0.25} \mathrm{O}_{3-\delta}$ (LSFN) with $\mathrm{x}=0$, 0.50, $0.75{ }^{11} \mathrm{X}$-ray powder diffractograms confirmed that the samples had rhombohedral symmetry (space group: $R-3 c$, space group number: 167), with a barely noticeable contamination of a tetragonal phase. ${ }^{12}$ The four-point dc conductivity shows the same trend like in Ref. 11. For VB PES measurements the fine powders were uniaxially pressed into disks $(\sim \varnothing 13 \mathrm{~mm})$ at $40 \mathrm{KN}$ and then sintered at $1673 \mathrm{~K}$ for $12 \mathrm{~h}$. Photoemission spectra were recorded at end station ${ }^{13}$ at beamline 9.3.2 of the Advanced Light Source, Lawrence Berkeley National Laboratory. The energy resolution of the beamline is $\mathrm{E} / \Delta \mathrm{E}=3000 .{ }^{14}$ The spectra were recorded in the maximum transmission mode. During measurements the base pressure of the main chamber was maintained at $10^{-9}$ Torr. The resonant VB PES spectra for Fe metal were measured using photon energies between 704 and $716 \mathrm{eV}$, leading up to the $2 p_{3 / 2}$ resonance energies. NEXAFS spectra were measured at beamline 8.0.1 in total electron yield mode at $300 \mathrm{~K}$. 

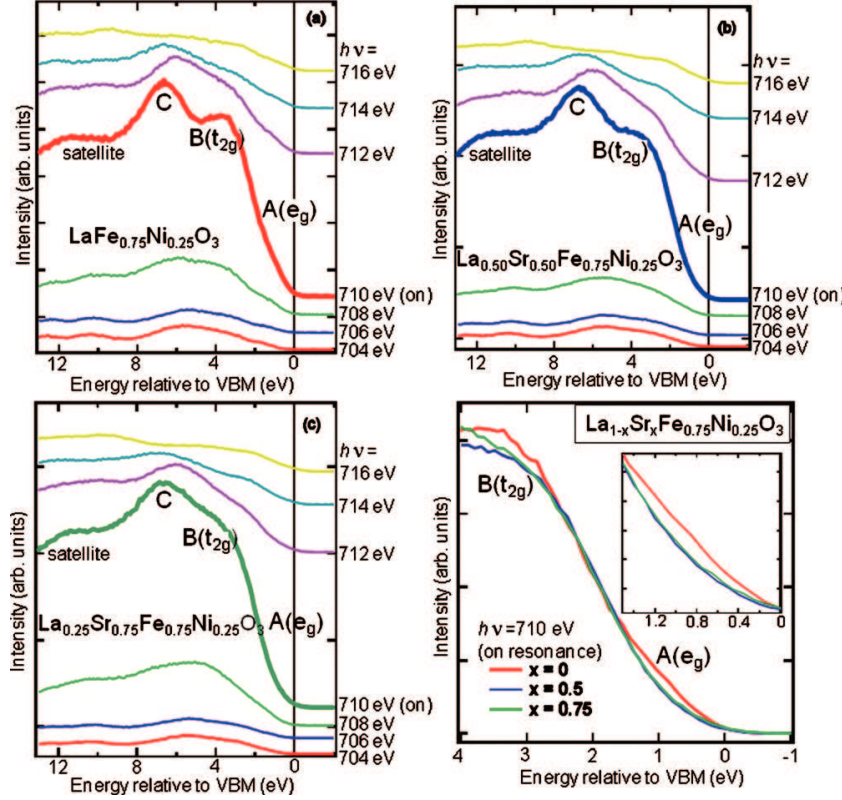

FIG. 1. (Color) Fe $2 p-3 d$ resonant VB PES spectra of $\mathrm{La}_{1-\mathrm{x}} \mathrm{Sr}_{\mathrm{x}} \mathrm{Fe}_{0.75} \mathrm{Ni}_{0.25} \mathrm{O}_{3}$. There is on-resonance condition at $710 \mathrm{eV}$. (a) $\mathrm{x}=0$, (b) $\mathrm{x}=0.50$, (c) $\mathrm{x}=0.75$. (d) Expanded VB PES spectra at Fe $2 p-3 d$ onresonance $(710 \mathrm{eV})$, with an inset showing that the intensity for $\mathrm{x}=0.75$ is in between those for $\mathrm{x}=0$ and 0.5 .

Figures 1(a)-1(c) show the VB PES spectra of $\mathrm{La}_{1-\mathrm{x}} \mathrm{Sr}_{x} \mathrm{Fe}_{0.75} \mathrm{Ni}_{0.25} \mathrm{O}_{3-\delta}$ for $\mathrm{x}=0.0,0.50$, and 0.75 obtained by tuning the excitation photon energy across the $\mathrm{Fe} 2 p$ $\rightarrow 3 d$ absorption threshold. The expanded VB PES spectra at Fe $2 p-3 d$ on-resonance $(710 \mathrm{eV})$ are shown in Fig. 1(d). Figure 2 shows the normalized $\mathrm{Fe}_{3}\left(2 p_{3 / 2}\right)$ and $\mathrm{L}_{2}\left(2 p_{1 / 2}\right)$ $\mathrm{x}$-ray absorption spectra for $\mathrm{x}=0$ and $\mathrm{x}=0.50$, marked with the energy positions, at which the resonant PES data were recorded. The Fe $\mathrm{L}$ edge is split into an $\mathrm{L}_{3}$ and $\mathrm{L}_{2}$ multiplet due to the core hole spin orbit coupling. The $\mathrm{L}_{3}$ and $\mathrm{L}_{2}$ edges are additionally split by the crystal field into peaks from transitions that arise from states with $\mathrm{t}_{2 \mathrm{~g}}$ and $\mathrm{e}_{\mathrm{g}}$ orbital symmetry. Visual inspection of the two spectra suggests that the sharp multiplet for $\mathrm{x}=0$ corresponds to $\mathrm{Fe}$ with predominant $\mathrm{Fe}^{3+}$ valence, whereas the more broad multiplet for $\mathrm{x}=0.5$ corresponds to $\mathrm{Fe}$ with a mixed valence between $\mathrm{Fe}^{3+}$ and $\mathrm{Fe}^{4+}$, particularly because of the relatively less intense $t_{2 \mathrm{~g}}$ structure in the $\mathrm{L}_{3}$ edge. Comparison of simulated spectra based on atomic multiplet theory and measured spectra indeed shows that a very good match is obtained when for $\mathrm{x}$
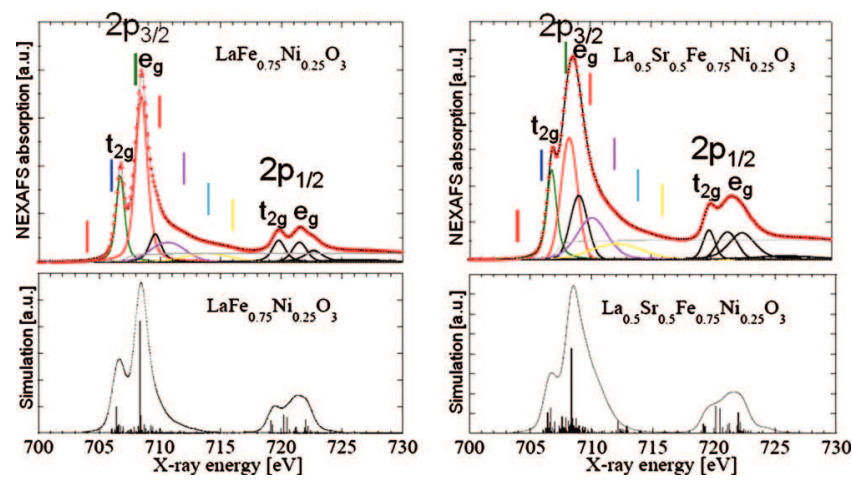

FIG. 2. (Color) Top panels-Normalized $\mathrm{Fe}_{2,3}$ edge $\mathrm{x}$-ray absorption spectra of $\mathrm{La}_{1-\mathrm{x}} \mathrm{Sr}_{\mathrm{x}} \mathrm{Fe}_{0.75} \mathrm{Ni}_{0.25} \mathrm{O}_{3}$ for $\mathrm{x}=0$ and $\mathrm{x}=0.50$. Vertical lines denote the energies where VB PES spectra were collected. Bottom panels-atomic multiplet simulation spectra for the same stoichiometries.
$=0 \mathrm{Fe}$ is entirely $\mathrm{Fe}^{3+}$, and for $\mathrm{x}=0.5 \mathrm{Fe}$ is to equal amounts in $\mathrm{Fe}^{3+}(50 \%)$ and in $\mathrm{Fe}^{4+}(50 \%)$, all of which in the high spin state. ${ }^{11}$

All spectra are normalized to the photon flux. The resonant enhancement of the spectral intensity at $710 \mathrm{eV}$ (on-resonance), which reflects the Fe $3 d$ partial density of states of LSFN, is clear. It is instructive to enter the discussion of the spectral features of LSFN by referring to the previously discussed VB PES spectra of $\mathrm{La}_{1-\mathrm{x}} \mathrm{Sr}_{\mathrm{x}} \mathrm{FeO}_{3-\delta}{ }^{15}$ The VB spectra are known to consist of four principal structures, i.e., an $\mathrm{e}_{\mathrm{g}}$ state $(\mathrm{A})$ near the Fermi energy, a state with $\mathrm{t}_{2 \mathrm{~g}}$ symmetry $(\mathrm{B})$, the $\mathrm{Fe} 3 d-\mathrm{O} 2 p$ bonding state peak $(\mathrm{C})$, and a charge transfer satellite (D). ${ }^{15}$ The $\mathrm{La}_{1-\mathrm{x}} \mathrm{Sr}_{\mathrm{x}} \mathrm{Fe}_{0.75} \mathrm{Ni}_{0.25} \mathrm{O}_{3-\delta}$ samples studied here are polycrystalline sintered bodies with a finite porosity. Such samples have a larger surface-to-volume ratio than single crystals. It is known that $\mathrm{La}_{1-\mathrm{x}} \mathrm{Sr}_{\mathrm{x}} \mathrm{FeO}_{3-\delta}$ surfaces are slightly understoichiometric and oxygen deficient, thus providing the iron atoms near the surface a less than sixfold octahedral coordination. This may be a reason why the VB structures near $E_{F}$, particularly the $t_{2 g}$ and $e_{g}$ structures are less pronounced in our sintered polycrystalline samples than those in single crystals.

A comparison of the VB PES spectra for $\mathrm{La}_{1-\mathrm{x}} \mathrm{Sr}_{\mathrm{x}} \mathrm{FeO}_{3-\delta}$ and $\mathrm{La}_{1-x} \mathrm{Sr}_{\mathrm{x}} \mathrm{Fe}_{0.75} \mathrm{Ni}_{0.25} \mathrm{O}_{3-\delta}$ shows that the $\mathrm{e}_{\mathrm{g}}$ peak (A) is virtually absent in $\mathrm{La}_{1-\mathrm{x}} \mathrm{Sr}_{x} \mathrm{Fe}_{0.75} \mathrm{Ni}_{0.25} \mathrm{O}_{3-\delta}$; there is a clear $\mathrm{t}_{2 \mathrm{~g}}$ feature (B) at around $3.5 \mathrm{eV}$. As well as the $\mathrm{O} 2 p$ bonding peak at around $7.5 \mathrm{eV}$ and the satellite at around $11.5 \mathrm{eV}$. Closer inspection of the on-resonance with $\mathrm{h} \nu=710 \mathrm{eV}$ in Fig. 1(d), which displays the features magnified in the energy range from -1.0 to $4.0 \mathrm{eV}$, shows that the intensity of the spectrum for $\mathrm{x}=0$ is enhanced for $0.20 \mathrm{eV}<\mathrm{E}<1.70 \mathrm{eV}$ in comparison to the spectra for $\mathrm{x}=0$ and 0.75 , and thus identify the structure at around $0.9 \mathrm{eV}$ as from the $\mathrm{e}_{\mathrm{g}}$ symmetry derived transition corresponding to the one known for $\mathrm{LaFeO}_{3} \cdot{ }^{15}$ Upon substitution of Sr by $50 \%$ and by $75 \%$, this $\mathrm{e}_{\mathrm{g}}$ (A) structure is not noticeable anymore. The next observation is that the energy position of the $t_{2 g}$ (B) structure seems to move towards higher binding energy, i.e., from 3.5 $\mathrm{eV}$ for $\mathrm{x}=0$ to just below $4.0 \mathrm{eV}$ for $\mathrm{x}=0.5$, and also for $\mathrm{x}$ $=0.75$. This is in contrast to observations made on $\mathrm{La}_{1-\mathrm{x}} \mathrm{Sr}_{\mathrm{x}} \mathrm{FeO}_{3-\delta}$. It appears also that the relative intensity of the $t_{2 g}$ peak decreases when $x$ is increasing. Thus, the general picture is that spectral intensity moves away from the Fermi energy $\mathrm{E}_{\mathrm{F}}$ with increasing substitution parameter $\mathrm{x}$, as it is particularly evidenced for the peaks due to transitions from states with the $e_{g}$ and $t_{2 g}$ orbital symmetry. For $\mathrm{La}_{1-\mathrm{x}} \mathrm{Sr}_{\mathrm{x}} \mathrm{FeO}_{3-\delta}$, the intensity decrease in the $\mathrm{e}_{\mathrm{g}}$ (A) structure upon $\mathrm{Sr}$ substitution was rationalized by transfer of doped electron holes towards the Fe $\mathrm{e}_{\mathrm{g}}$ band. $^{8}$

Since states with $\mathrm{e}_{\mathrm{g}}$ orbital symmetry correspond to $\mathrm{Fe}$ in octahedral coordination with the oxygen ions, the diminishing of the $e_{\mathrm{g}}$ state can thus be interpreted as a deviation of crystal field effect in octahedral coordination: the crystal field effect increases from $1.80 \mathrm{eV}$ to $1.85 \mathrm{eV}$ by substituting $\mathrm{Fe}$ with $\mathrm{Ni}^{12}{ }^{12} \mathrm{We}$, therefore, conclude that substitution of $\mathrm{Fe}$ by $\mathrm{Ni}$, too, leads to formation of electron holes, which move to the $\mathrm{Fe} \mathrm{e}_{\mathrm{g}}$ bands, and therefore, $\mathrm{Ni}$ substitution has the similar effect on the depletion of the $\mathrm{e}_{\mathrm{g}}$ structure like $\mathrm{Sr}$ substitution. In addition, as evidenced in our spectra, the established trend that substitution of $\mathrm{La}$ by $\mathrm{Sr}$ increases the doped hole concentration in $\mathrm{La}_{1-x} \mathrm{Sr}_{\mathrm{x}} \mathrm{FeO}_{3-\delta}$, is also recovered in our LSFN samples: The hole states formed upon $\mathrm{Sr}$ 

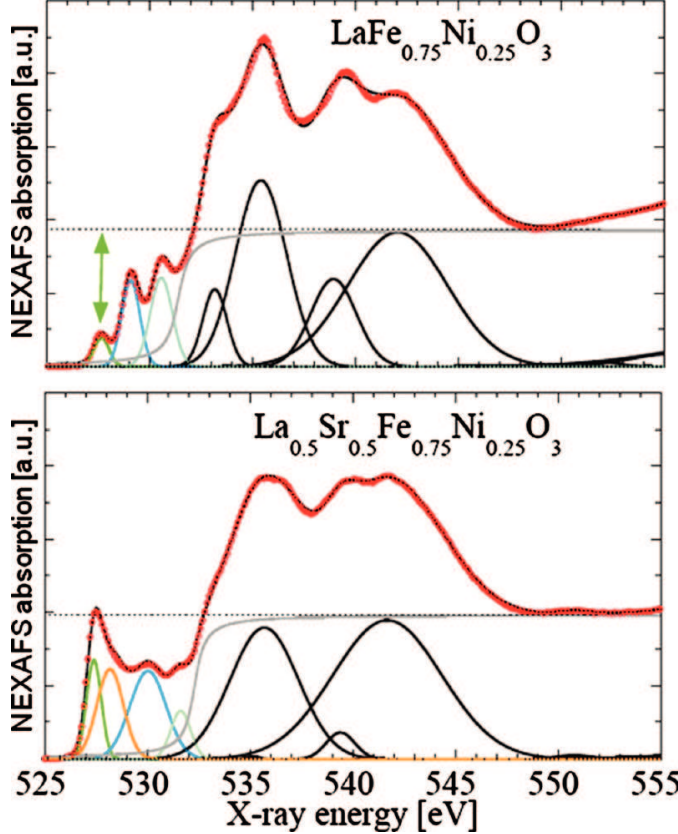

FIG. 3. (Color) Normalized $\mathrm{O} \mathrm{K}$ edge $\mathrm{x}$-ray absorption spectra of $\mathrm{La}_{1-\mathrm{x}} \mathrm{Sr}_{\mathrm{x}} \mathrm{Fe}_{0.75} \mathrm{Ni}_{0.25} \mathrm{O}_{3}$ for $\mathrm{x}=0$, and $\mathrm{x}=0.50$ with suggested peak deconvolution into Voigt functions. Arrow in top panel spectrum shows the difference between $\mathrm{e}_{\mathrm{g}} \uparrow$ peak intensity and normalization level (dashed horizontal line). Spectrum in bottom panel has additional peak at $\sim 528 \mathrm{eV}$.

substitution in $\mathrm{La}_{1-\mathrm{x}} \mathrm{Sr}_{\mathrm{x}} \mathrm{FeO}_{3-\delta}$ and LSFN deplete the $\mathrm{e}_{\mathrm{g}}$ states. This suggestion finds further confirmation when looking at the oxygen NEXAFS spectra of $\mathrm{La}_{1-\mathrm{x}} \mathrm{Sr}_{\mathrm{x}} \mathrm{Fe}_{0.75} \mathrm{Ni}_{0.25} \mathrm{O}_{3-\delta}$ for $\mathrm{x}=0$ and 0.5, as shown in Fig. 3 .

$\mathrm{La}_{1-\mathrm{x}} \mathrm{Sr}_{\mathrm{x}} \mathrm{FeO}_{3-\delta}$ has an $\mathrm{e}_{\mathrm{g}}$ spin up orbital symmetry state from doped holes, and $\mathrm{a}_{2 \mathrm{~g}}$ and $\mathrm{e}_{\mathrm{g}}$ spin down doublet from hybridized $\mathrm{O} 2 p-\mathrm{Fe} 3 d$ states as the $\mathrm{O} 1 s$ NEXAFS preedge structure. The intensities of the $\mathrm{e}_{\mathrm{g}} \underset{15}{\text { states }}$ in $\mathrm{La}_{1-x} \mathrm{Sr}_{\mathrm{x}} \mathrm{FeO}_{3-\delta}$ scale roughly with the $\mathrm{Sr}$ content. ${ }^{15}$

Due to the exponential dependence between the relative spectral intensity ratio $e_{g} \uparrow /\left(t_{2 g} \downarrow+e_{g} \downarrow\right)$ and the conductivity was found, ${ }^{16}$ it is possible to investigate the transport property of this type material through their pre-edge structures. $\mathrm{La}_{1-\mathrm{x}} \mathrm{Sr}_{\mathrm{x}} \mathrm{Fe}_{0.75} \mathrm{Ni}_{0.25} \mathrm{O}_{3-\delta}$ with $\mathrm{x}=0$ has a small such leading $\mathrm{e}_{\mathrm{g}} \uparrow$ peak, which supports the aforementioned suggestion that Ni substitution has the same effect like hole doping. It has recently been shown that increasing $\mathrm{Ni}$ concentration in $\mathrm{LaFe}_{1-\mathrm{x}} \mathrm{Ni}_{\mathrm{x}} \mathrm{O}_{3}$ increases the intensity of prepeak and also shifts it towards $\mathrm{E}_{\mathrm{F}}{ }^{17}$ The intensity of the corresponding $\mathrm{e}_{\mathrm{g}}$ spin up peak in $\mathrm{La}_{1-\mathrm{x}} \mathrm{Sr}_{\mathrm{x}} \mathrm{Fe}_{0.75} \mathrm{Ni}_{0.25} \mathrm{O}_{3-\delta}$ for $\mathrm{x}=0.50$ is much higher than the intensity of that for $\mathrm{x}=0$, i.e., by a factor of six. In addition we do notice a small shift in the $\mathrm{e}_{\mathrm{g}}$ spin up peak energy position toward $\mathrm{E}_{\mathrm{F}}$ upon hole doping. We have recently shown that, since the $\mathrm{Ni} 3 d$ states are closer to $\mathrm{E}_{\mathrm{F}}$ than the $\mathrm{Fe} 3 d$ states, the doped holes go predominantly to $\mathrm{Ni}^{11}{ }^{11}$ The changes in the electronic structure of the $\mathrm{La}_{1-\mathrm{x}} \mathrm{Sr}_{\mathrm{x}} \mathrm{Fe}_{0.75} \mathrm{Ni}_{0.25} \mathrm{O}_{3-\delta}$ upon $\mathrm{Sr}$ substitution are qualitatively reflected by the electrical conductivity, as shown in ref. 11. The well known conductivity maximum of $\mathrm{La}_{1-\mathrm{x}} \mathrm{Sr}_{\mathrm{x}} \mathrm{FeO}_{3-\delta}$ at $\mathrm{x}=0.50$ is also observed for $\mathrm{La}_{1-\mathrm{x}} \mathrm{Sr}_{\mathrm{x}} \mathrm{Fe}_{0.75} \mathrm{Ni}_{0.25} \mathrm{O}_{3-\delta}$ for the same $\mathrm{x}$; this is also corroborated by the $e_{g} \uparrow$ peak intensity in the oxygen NEXAFS spectra for $x=0$ and 0.50 , see Fig. 3 .

The influence of the Ni-when to $25 \%$ substituting the $\mathrm{Fe}$ in $\mathrm{La}_{1-\mathrm{x}} \mathrm{Sr}_{\mathrm{x}} \mathrm{FeO}_{3-\delta}$-on the conductivity and on the electronic structure appears clear now. However, the mechanism of how the Ni interacts in relation to the Fe with oxygen is not yet clear. Quite interestingly, we notice that the $\mathrm{e}_{\mathrm{g}}$ intensity for $x=0.75$ in the VB PES is a little yet noticeable larger than that for $\mathrm{x}=0.50$. The same holds for the larger extent for the $\mathrm{t}_{2 \mathrm{~g}}$ intensity, corroborating how the electrical conductivity depends systematically on the VB PES intensity.

We have performed resonant VB PES, and NEXAFS at the $\mathrm{O} \mathrm{K}$ edge and $\mathrm{Fe} \mathrm{L}_{2,3}$ edges on $\mathrm{La}_{1-\mathrm{x}} \mathrm{Sr}_{\mathrm{x}} \mathrm{Fe}_{0.75} \mathrm{Ni}_{0.25} \mathrm{O}_{3-\delta}$ $\left(\mathrm{x}=0.0,0.5\right.$, and 0.75). The spectral weight of occupied $\mathrm{e}_{\mathrm{g}}$ and $\mathrm{t}_{2 \mathrm{~g}}$ states of $\mathrm{Fe}$ is reduced upon electron hole doping up to $50 \%$ and then starts to increase which is parallel to changes in electrical conductivity. The spectral weight of the prepeak in the oxygen NEXAFS spectra due to the p-type electron holes created on $\mathrm{Ni} 3 d$ increases with increasing $\mathrm{x}$. With respect to $\mathrm{La}_{1-x} \mathrm{Sr}_{x} \mathrm{FeO}_{3}$, it is observed that the spectral weight transfers from below $\mathrm{E}_{\mathrm{F}}$ to above it across the gap. However, here in $\mathrm{La}_{1-\mathrm{x}} \mathrm{Sr}_{\mathrm{x}} \mathrm{Fe}_{0.75} \mathrm{Ni}_{0.25} \mathrm{O}_{3-\delta}$ it is difficult to conclude this since the Ni $3 d$ states are located closer to $\mathrm{E}_{\mathrm{F}}$ than those of the $\mathrm{Fe} 3 d$ and we do not consider any metalmetal ( $\mathrm{Fe}-\mathrm{Ni}$ and/or Ni-Fe) electron hole transfer.

Funding by E.U. MIRG under Grant No. CT-2006042095, Swiss NSF under Grant No. 200021-116688, Swiss Federal Office of Energy under Project No. 100411. The ALS is supported by the Director, Office of Science/BES, of the U.S. DoE, Grant No. DE-AC02-05CH11231. The authors would like to thank Dr. Wanli Yang and student Paul Olalde Valesco from ALS for their help during XAS measurements.

${ }^{1}$ M. Imada, A. Fujimori, and Y. Tokura, Rev. Mod. Phys. 70, 1039 (1998). ${ }^{2}$ C. Sun, R. Hui, and J. Roller, J. Solid State Electrochem. 14, 1125 (2010). ${ }^{3}$ V. V. Kharton, A. P. Viskup, A. A. Yaremchenko, R. T. Baker, B. Gharbage, G. C. Mather, F. M. Figueiredo, E. N. Naumovich, and F. M. B. Marques, Solid State Ionics 132, 119 (2000).

${ }^{4}$ A. Braun, A. Ovalle, V. Pomjakushin, A. Cervellino, S. Erat, W. C. Stolte, and T. Graule, Appl. Phys. Lett. 95, 224103 (2009).

${ }^{5}$ R. Chiba, F. Yoshimura, and Y. Sakurai, Solid State Ionics 152-153, 575 (2002).

${ }^{6}$ E. V. Tsipis, E. A. Kiselev, V. A. Kolotygin, J. C. Waerenborgh, V. A. Cherepanov, and V. V. Kharton, Solid State Ionics 179, 2170 (2008).

${ }^{7}$ T. Montini, M. Bevilacqua, E. Fonda, M. F. Casula, S. Lee, C. Tavagnacco, R. J. Gorte, and P. Fornasiero, Chem. Mater. 21, 1768 (2009).

${ }^{8}$ H. Wadati, D. Kobayashi, A. Chikamatsu, R. Hashimoto, M. Takizawa, K. Horiba, H. Kumigashira, T. Mizokawa, A. Fujimori, M. Oshima, M. Lippmaa, M. Kawasaki, and H. Koinuma, J. Electron Spectrosc. Relat. Phenom. 144-147, 877 (2005).

${ }^{9}$ M. L. Medarde, J. Phys.: Condens. Matter 9, 1679 (1997).

${ }^{10}$ A. Chainani, M. Mathew, and D. D. Sarma, Phys. Rev. B 48, 14818 (1993).

${ }^{11}$ S. Erat, A. Braun, A. Ovalle, C. Piamonteze, Z. Liu, T. Graule, and L. J. Gauckler, Appl. Phys. Lett. 95, 174108 (2009).

${ }^{12}$ S. Erat, A. Braun, C. Piamonteze, Z. Liu, A. Ovalle, T. Graule, and L. J. Gauckler, "Entanglement of charge transfer, hole doping, exchange interaction and octahedron tilting angle and their influence on the conductivity of $\mathrm{La}_{1-\mathrm{x}} \mathrm{Sr}_{\mathrm{x}} \mathrm{Fe}_{0.75} \mathrm{Ni}_{0.25} \mathrm{O}_{3-\delta}$ : A combination of $\mathrm{x}$-ray spectroscopy and diffraction," J. Appl. Phys. (to be published).

${ }^{13}$ M. E. Grass, P. G. Karlsson, F. Aksoy, M. Lundqvist, B. Wannberg, B. S. Mun, Z. Hussain, and Z. Liu, Rev. Sci. Instrum. 81, 053106 (2010).

${ }^{14}$ Z. Hussain, W. R. A. Huff, S. A. Kellar, E. J. Moler, P. A. Heimann, W. McKinney, H. A. Padmore, C. S. Fadley, and D. A. Shirley, J. Electron Spectrosc. Relat. Phenom. 80, 401 (1996).

${ }^{15}$ H. Wadati, D. Kobayashi, H. Kumigashira, K. Okazaki, T. Mizokawa, A. Fujimori, K. Horiba, M. Oshima, N. Hamada, M. Lippmaa, M. Kawasaki, and H. Koinuma, Phys. Rev. B 71, 035108 (2005).

${ }^{16}$ A. Braun, D. Bayraktar, S. Erat, A. S. Harvey, D. Beckel, J. A. Purton, P. Holtappels, L. J. Gauckler, and T. Graule, Appl. Phys. Lett. 94, 202102 (2009).

${ }^{17}$ D. D. Sarma, O. Rader, T. Kachel, A. Chainani, M. Mathew, K. Holldack, W. Gudat, and W. Eberhard, Phys. Rev. B 49, 14238 (1994). 